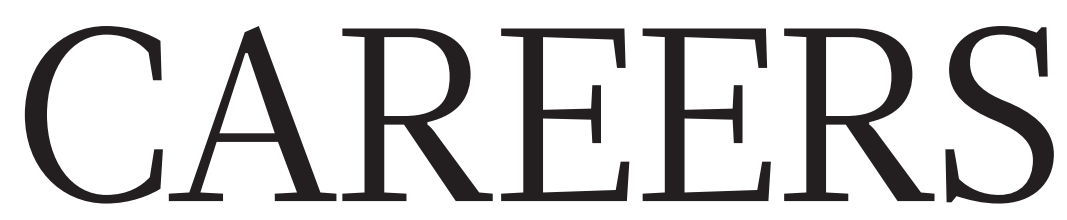

PRICED OUT Living expenses force Oxford postdoc into industry $\mathbf{p} . \mathbf{2 4 9}$
BLOG Personal stories and careers counsel blogs.nature.com/naturejobs
NATUREJOBS For the latest career

listings and advice www.naturejobs.com

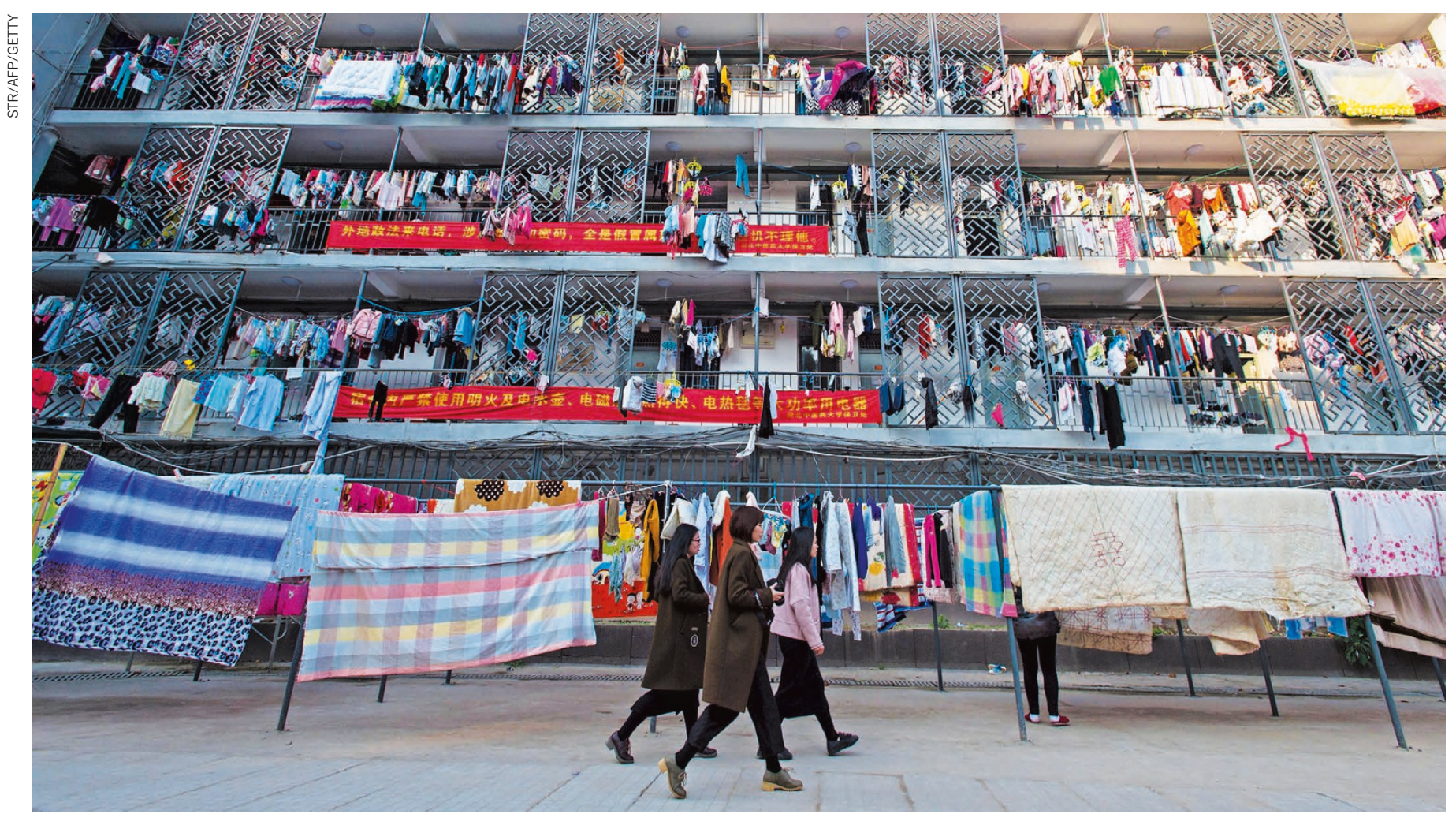

Working or studying in an expensive city can often mean compromising on space or sharing with roommates.

\title{
HOUSING
}

\section{A home on a budget}

\section{Affordable dwellings are rare in many areas where junior researchers want to study or work.}

\section{BY CHRIS WOOLSTON}

A lastair Loutit had a lot on his plate in the first months of his neuroscience $\mathrm{PhD}$ at the University of New South Wales in Sydney, Australia. He had to get acquainted with the lab, plan his first experiments and find the best places to train for his bicycle road races.

But as a newcomer to the city, Loutit also had something else preying on his mind: finding a place to live that wouldn't destroy his budget. "My girlfriend and I looked around for about two months," he says. "It's ridiculous in Sydney. There are one-bedroom apartments with no kitchen and a bathroom that you share with other people for Aus $\$ 450$ (US\$337.90) a week."

From Sydney to Paris, London to San Francisco, junior researchers run up against the same problem: some of the most prestigious and sought-after places to study and work also have the highest housing costs. Whether graduate students and postdocs are looking to rent or buy, putting a roof over their heads can be a challenge on their often modest incomes (see page 249).

Yet many scientists jump into $\mathrm{PhD}$ programmes or postdoc positions without ever considering local housing costs, says Emily Roberts, who co-founded the Evolving Personal Finance blog with her husband Kyle in 2014. Its sister site, gradstudentfinances.org, offers financial tips for PhD students. "You can go into a programme that fits your passion and gives you the best training, but you should keep your eyes open about costs," she says. To survive, Roberts adds, researchers need to familiarize themselves with the local housing markets (see 'Room for rent'), find out about available subsidies and support programmes and be willing to compromise. And that may mean setting the bar for accommodation lower than they might hope.

Roberts, who has a $\mathrm{PhD}$ in biomedical engineering from Duke University in the relatively budget-friendly city of Durham, North Carolina, had to do some number crunching herself when her husband secured a postdoc position in much pricier Boston, Massachusetts. "After we adjusted for cost of living and taxes, his pay would have been less than what he was making as a graduate student in Durham," she says. Faced with that reality, he declined the offer.

Living in a pricey city almost always involves trade-offs, Roberts says. She recently gave financial talks to $\mathrm{PhD}$ students in New York 
> City and Palo Alto, California - two of the most expensive science hubs in the United States. "The choices there are hard and really unpalatable," she says. Many graduate students and postdocs live with roommates or opt for tiny flats in no-frills buildings. Others choose a place far from the lab, but that decision has its own costs. "Long commutes," she says, "can really affect your career progress".

\section{MAKING ENDS MEET}

Lengthy home-to-lab trips were a daily nuisance for Gary McDowell during his postdoc. He travelled from Providence, Rhode Island, to Boston, a trip of at least an hour each way. McDowell and his husband had rented a single room in a twobedroom apartment in Cambridge, Massachusetts, for \$1,300 a month, but they discovered that they could have a whole apartment in Providence for the same price. The commute forced him to boost his productivity at work, says McDowell, now executive director of Future of Research (FOR), an advocacy organization for junior scientists that is based in San Francisco, California. He had to keep his work and home life separate: it was no longer convenient to pop to the lab at nights or weekends, so he needed to get his experiments done during the week.

Researchers in some pricey areas can get help to ease the burden. Postdocs at Columbia University in New York City can apply for subsidized housing near the campus, but demand always outstrips supply. In the United Kingdom, recipients of Medical Research Council $\mathrm{PhD}$ stipends get an extra $£ 2,000(\$ 2,586)$ per year if they study in London.

The unionized postdocs in the University of California system used the high cost of living as a bargaining tool when they negotiated a contract that pays new researchers a minimum of $\$ 48,216$ a year, which is equivalent to the US National Institutes of Health's scale for postdocs with two years of experience. In addition, the University of California, San Francisco, offers eligible students a cost-of-living supplement

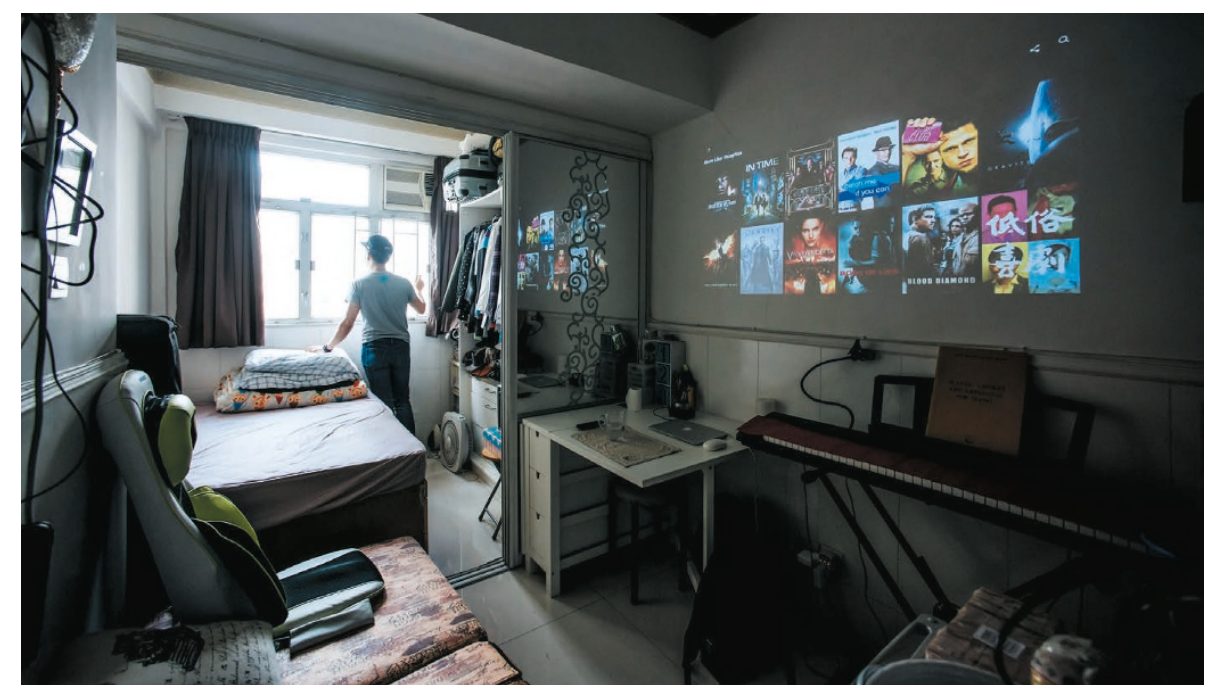

Cramped living spaces are common in cities such as Hong Kong that lack affordable housing. of $\$ 2,400$ for the school year. Considering that one-bedroom flats in the city generally cost more than $\$ 3,000$ a month, that generosity doesn't go far.

Oxford, UK, is another place where it's hard to make ends meet. According to an analysis by The Guardian newspaper in February 2017, the average price of a house in Oxford is $£ 385,372$. That is 10.7 times the average annual wage in the city - the largest such disparity in the country. For young researchers looking to rent, the picture isn't much brighter. "You can rent a two-bedroom house in Oxford for $£ 1,200$ to $£ 1,500$ a month," says Emma Davies, a psychology lecturer at Oxford Brookes University. "But the first job after a $\mathrm{PhD}$ might only pay $£ 35,000$ a year. That's a huge chunk of your salary going to housing costs. There's no way to save."

The Oxford housing crunch has complicated the university's recruitment efforts, Davies says. "We've had people say, 'There's no way I can come and work with you, because it costs too much"' she says.

At the University of Cambridge, UK, Ewan St John Smith says that he hasn't had trouble recruiting postdocs for his neuropharmacology lab. Still, he recognizes that a postdoc salary doesn't go far in the city, especially if someone is supporting a family. "In some places, it's really tough." Despite the university's prestige, housing prices have cost Cambridge some potential recruits. "If you're coming from up north you can afford in Cambridge, that's an issue," he says. Old, rundown houses are also a turn-off, he says. "We have Victorian housing that hasn't been updated since the 1970s," he says. "There's no pressure on landlords to renovate."

Poor-quality dwellings also abound in Paris, says Juliane Klamser, a physics $\mathrm{PhD}$ student at the École Normale Supérieure in central Paris (see Nature 546, 317-319; 2017). "A lot of apartments have broken glass, mould growing in the showers and old, broken furniture," she says. "As soon as you walk in, you just want to run away. where you have a nice big house and see what

\section{ROOM FOR RENT}

The cost of renting a one-bedroom flat in a city centre varies depending on the city. You can find bargains in Berlin and Beijing, but prepare to pay more in New York City and San Francisco.

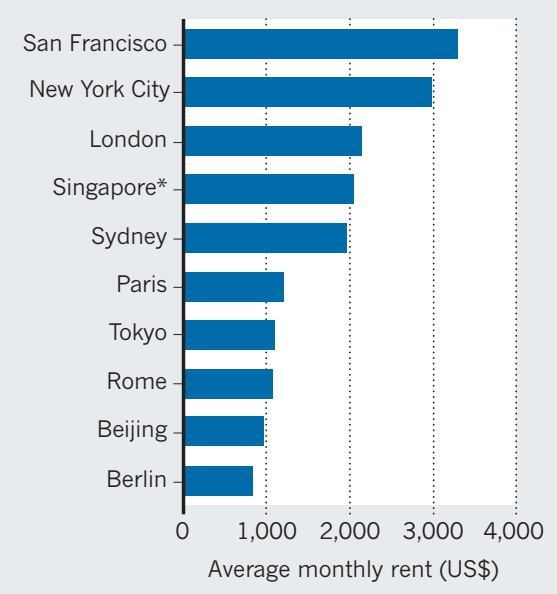

*Cost for a non-subsidized flat.

But they are still very expensive."

Klamser, who is from Germany, says that non-French people tend to end up with the worst housing in the country. "Most of the PhD students in my department are foreigners" she says. French laws strongly protect tenants, so landlords are very particular about whom they let housing to. As a rule, she says, landlords prefer to have a French person guarantee the lease, and they don't make exceptions for $\mathrm{PhD}$-level researchers. Many foreign students ask their $\mathrm{PhD}$ advisers to be guarantors, but Klamser says that she didn't know her supervisor well enough to ask. She endured a tiny, mould-tainted apartment for nearly a year before taking over a better place from a colleague.

Foreign students in Sydney often face an extra challenge when it comes to finding affordable housing, says Loutit, who is from Canberra. "They can't be over here looking around ahead of time," he says. The long distances between Sydney and cities in Europe or North America make doing so unfeasible. "And student housing runs out fast."

But expatriates fare better in other places. In Singapore, foreign postdocs at the Agency for Science, Technology and Research (A STAR) the country's largest research agency, receive substantial housing stipends. "A lot of them have a much nicer place than I do," says Ang Siang Yun, a Singapore citizen and biomedical postdoc at the Institute of Medical Biology. "They live in condos with swimming pools and fitness centres." She says that some international postdocs get a monthly stipend of 1,000 Singapore dollars (\$720) or more. An A*STAR spokesperson would not disclose details.

Still, she concedes that housing is more affordable in Singapore than it is elsewhere. She spent six years as a postdoc in San Francisco, and is struck by the contrast. "In San Francisco, 
the pay-to-rent ratio was harsh," she says. "In Singapore, it works out." She says that her postdoc salary is about double what she received in San Francisco, and she's paying about 1,000 Singapore dollars a month for a room in a three-bedroom flat that she shares with two other people.

\section{TAKE HOLD OF YOUR FINANCES}

Roberts advises scientists to research the costs of living when considering a career move. Once settled on a destination, she says, they should check out online groups, including Facebook, or university websites to find short-term housing options, whether that is a room in an flat or a campus dormitory. "That helps with the transition of going to a new city and grappling with a new market," she says. Researchers need to understand all the housing options before committing to a long-term lease.

Those who think that they've found an affordable place can still run into trouble if their pay rises don't keep pace with housing costs. "You might think you're doing OK in the first year in a new city, but things could get tighter in year five," Roberts says. When raising the issue with a supervisor, offer data, she advises. "If you say, 'My rent has gone up $10 \%$, but my stipend went up by $3 \%$, they might listen," she says. "Give them real numbers." Junior researchers also

"We've had. people say, 'There's no way I can come and work with you, because it costs too much'." shouldn't hesitate to talk numbers with their peers, Roberts says. It can help them to work out if they are getting value for money or to hear about other options. Such a strategy helped Roberts to make two moves during her graduate programme that significantly reduced her rent.

Of course, choosing to work or study in a relatively inexpensive city could relieve much of the pressure. St John Smith says that he had no trouble affording a flat in Berlin while he was a postdoc at the Max Delbrück Centre for Molecular Medicine. "The science is great, and you can have a high quality of life as a normal academic."

But with a little planning, young scientists who land a prime position in an expensive city don't have to let housing costs get in the way of their ambitions. Ang says that she plans to return to pricey San Francisco after finishing her postdoc in Singapore. And Klamser says that she never hesitated to move to Paris. "I knew the environment here was good for research, and there was no question of dropping it because it's expensive," she says. "You just go." -

Chris Woolston is a freelance writer in Billings, Montana.

\section{TURNING POINT}

Tenacious chemist

Elena Tobolkina, from St Petersburg, Russia, followed a PhD in Switzerland with a move in 2015 to the University of Oxford, UK, for her dream postdoc in chemistry. But just one year later, the high costs of UK housing and childcare drove her out. Now she is trying to forge a career in industry.

How did your career path lead you to Oxford? After I got my undergraduate degree in physical chemistry at St Petersburg State University, I moved to Switzerland to do my PhD in bioanalytical chemistry at the Swiss Federal Institute of Technology in Lausanne (EPFL). I published eight papers and received a patent for a mass-spectrometry technique. I completed my PhD in three and a half years, and was eight months pregnant when I graduated. While on maternity leave, I got the opportunity to work with the chemist Ben Davis at Oxford. It was a dream to get there, but a very difficult decision as my husband had a fulltime job in Switzerland. We decided I would go and that we'd determine later whether he would join me or I would return.

\section{What did you study during your postdoc?}

My project was in cooperation with the French cosmetics company L'Oréal. We were creating a methodology to develop products and detect age-related skin changes from their use. I can't overstate how much I loved my project.

\section{Why did you leave after a year?}

My postdoc salary was around $£ 1,900$ (US\$2,470) a month. Most off-campus housing requires you to rent a two-bedroom flat if you have a child, but I managed to get a onebedroom for $£ 1,650$. That was still double what my lab-mates paid to rent a room in a large home, but with a 5-month-old I couldn't be in a loud place. Then I needed to find childcare. As soon as I committed in March 2015 to going to Oxford, I applied for the nursery on campus but they were full, and it would have been $£ 1,100$ per month. So when we moved in May 2015, I arranged for a nanny from Russia to come with us. But she was deported during the Christmas break. I ended up sending my daughter to my parents in Russia and flew to see her once a month. It was impossible to live on my salary and was a very stressful, difficult time. I terminated my three-year contract after one year.

\section{What was your adviser's response?}

When I explained all my financial difficulties and that I had a child, he was shocked and extremely helpful. He suggested I write official

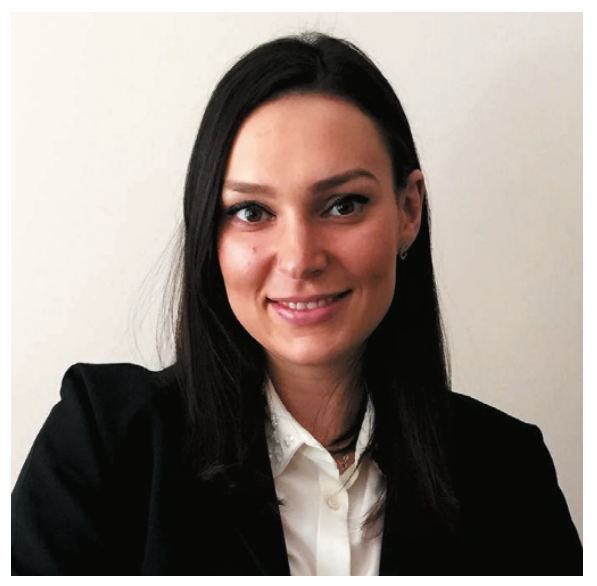

letters to the university, and he wrote a letter of support. He wanted me to continue but couldn't raise my salary much.

\section{What was the university's response?}

The big issue for housing is that postdocs are considered staff, not students, so there simply is no way to access affordable student accommodation through campus housing. The university said it was trying to increase the number of places in the nursery and was thinking of building other nursery schools, but that it would take time. As I wrote last year in Times Higher Education, it felt like I had to choose between my postdoc and my child.

\section{What did you do after you left Oxford?}

I worked on clinical trials related to Parkinson's disease at the EPFL, but I left in June and started as an associate scientist at the tobacco company Philip Morris International in Neuchatel, Switzerland. I determine whether chemicals in future liquid smoking products will be harmful for people.

\section{Have you explored other opportunities} in industry?

I was losing my motivation after leaving Oxford, but then I remembered my patent and have decided to try entrepreneurship. I took business and management classes while I was at the EPFL. My goal now is to launch a company and produce affordable technology that will help pharmaceutical or biomedical companies to run quality controls on their samples. Right now, I'm trying to create a business plan, put together a strong team and secure financing. It's all new to me.

\section{INTERVIEW BY VIRGINIA GEWIN}

This interview has been edited for length and clarity. 